\section{Viral meningitis in pregnancy: A case report}

\author{
Ruth Roseingrave* and Savita Lalchandani \\ Department of Obstetrics and Gynaecology, University Hospital Kerry, Tralee, Ireland
}

\section{Summary}

Ms $X$ is a 34 year old para 1 woman who presented at $26+5$ weeks' gestation with fever, neurological symptoms and history of a viral illness. She was treated empirically for bacterial meningitis and transferred to a tertiary maternity hospital. Cerebrospinal fluid (CSF) polymerase chain reaction (PCR) was positive for enteroviral ribonucleic acid (RNA), confirming viral meningitis. Ms X improved clinically and was discharged after six days. A high index of suspicion is required for diagnosis of meningitis in pregnancy. Thorough history, examination and workup is vital for timely treatment. Prognosis in viral meningitis is excellent with no clear adverse fetal or neonatal outcomes.

\section{Introduction}

Viral meningitis is an inflammation of the meninges [1] caused by viral infection of the central nervous system. It is typically self-limiting with low morbidity. However, it is impossible to clinically differentiate between viral and bacterial meningitis, which is associated with high maternal and fetal morbidity and mortality. Few cases of viral meningitis are reported in the literature. We present the case of Ms X, a 34 year old para 1 woman who presented to the Emergency Department (ED) at 26+5 weeks' gestation with sudden onset headache, photophobia, fever and generalised aches. Her history was significant for a flu-like illness for five days prior, and she was taking oral antibiotics prescribed by her GP. Ms X had no obstetric complaints and was happy with fetal movements. The case occurred prior to the SARS-COV2 pandemic and thus no investigations for coronavirus were required at the time.

\section{Results}

On assessment by the medical team in the emergency department, Ms X was pyrexial at 38.3 degrees Celsius. Chest X-ray and brain computerised tomography (CT) were normal. Bloods revealed mild leucocytosis of $12.6 \times 10^{9} / \mathrm{L}$ and neutrophilia of $10.03 \times 10^{9} / \mathrm{L}$, with a CRP of $44.5 \mathrm{mg} / \mathrm{L}$. Lumbar puncture showed a white cell count of $170 / \mathrm{cmm}$, red cell count of $19 / \mathrm{cmm}$, glucose $2.7 \mathrm{mmol} / \mathrm{L}$ and protein 93 $\mathrm{mg} / \mathrm{dL}$. Leishman stain revealed $20 \%$ polymorphs and $80 \%$ lymphocytes. Gram stain was negative, and CSF was sent for culture, sensitivity and multiplex real time polymerase chain reaction (PCR). Urine and blood were sent for culture and sensitivity.

\section{More Information}

*Address for Correspondence: Dr. Ruth Roseingrave, Department of Obstetrics and Gynaecology, University Hospital Kerry, Tralee, Co. Kerry, Ireland, Email: roseingr@tcd.ie

Submitted: 15 June 2020

Approved: 12 October 2020

Published: 13 October 2020

How to cite this article: Roseingrave $R$, Lalchandani S. Viral meningitis in pregnancy: A case report. Clin J Obstet Gynecol. 2020; 3: 121-122.

DOI: 10.29328/journal.cjog.1001063

Copyright: @ 2020 Roseingrave R, et al. This is an open access article distributed under the Creative Commons Attribution License, which permits unrestricted use, distribution, and reproduction in any medium, provided the original work is properly cited.

\section{Check for updates}

OPEN ACCESS
Obstetric examination was unremarkable. Fundal height corresponded to dates, with normal fetal heart rate. Obstetric ultrasound scan showed an active fetus with normal growth and liquor volume.

After discussion with the consultant microbiologist, intravenous (IV) antibiotics were administered for empiric treatment of suspected bacterial meningitis. Ms X was transferred to a tertiary maternity hospital due to her gestation, the risk of clinical deterioration, and for access to a multidisciplinary team (MDT) including on-site neurology, microbiology and infectious diseases. IV acyclovir was added to cover herpes simplex virus (HSV) encephalitis.

By evening, Ms X was apyrexial with no photophobia. Urine, blood and CSF cultures were negative. CSF PCR was positive for enteroviral RNA. No further testing was carried out to determine the enteroviral species at the time. Antibiotics and antiviral drugs were discontinued, and Ms X was discharged by the MDT. Ms X was discharged after six days with regular follow-up appointments in a medical obstetric unit with close maternal and fetal monitoring. The remainder of the pregnancy was uneventful. At 41 weeks Ms X had an induction of labour for post-dates and an uncomplicated vaginal delivery of a healthy infant.

\section{Discussion}

Enteroviral meningitis complicating pregnancy is a rare occurrence. 336 cases of viral meningitis were reported in Ireland in 2018 (7.2 per 100,000 population), the majority of 
which were enteroviral [2]. Accordingly, 85\% of cases of viral meningitis worldwide are caused by enteroviruses [3]. Other causative organisms include arboviruses, mumps viruses and herpes family viruses.

The presenting complaint in cases such as this may make a timely diagnosis challenging. Differential diagnoses may include a wide range of infectious and non-infectious causes such as pre-eclampsia, cerebral haemorrhage, stroke, migraine or a systemic inflammatory response associated with another source of infection. Bacterial meningitis cannot be out ruled without further investigations, but in light of Ms X's temperature of 38 degrees Celsius combined with her neurological symptoms, a high degree of suspicion for meningitis and immediate recourse to urgent laboratory processing is required to reduce time to diagnosis.

Diagnostic methods for rapid and accurate identification of pathogens have improved over recent years, permitting more precise and earlier diagnoses [4]. Investigations include serum inflammatory markers, blood culture and serum glucose measurements [5]. Lumbar puncture for culture and PCR is the cornerstone of diagnosis, as it can determine the causative organism and appropriate treatment. Of note, culture may be negative in a partially treated bacterial meningitis.

There have been fewer developments in therapies for viral meningitis, and there remain no effective treatment for most pathogens. Management is supportive. Antibiotics can be given while awaiting cultures if clinically indicated [6], as well as antivirals if HSV encephalitis is suspected. Antifungal, antituberculous or antiretroviral medication should be considered if appropriate and following consultation with microbiology and infectious disease specialists [7].

Complications are rare but include encephalitis, encephalomyelitis and communicating hydrocephalus. Intensive care unit admission may be required for airway support or managing complications. If there are no complications, viral meningitis is self-limiting over 7-10 days.

A small number of cases of viral meningitis in pregnancy complicated by encephalitis can be found in the literature. One woman required haemodialysis and emergency caesarean section in the maternal interest due to acute onset of HSV encephalitis at 33 weeks' gestation [8]. Another developed encephalitis associated with West Nile virus meningitis at 38 weeks' gestation [9]. Both patients were treated with empirical antimicrobial and antiviral therapies, and given supportive treatment and close fetal monitoring $[8,9]$.

\section{Conclusion}

Enteroviral meningitis complicating pregnancy is a rare occurrence. Accurate and timely diagnosis, and a high index of suspicion is required. Lumbar puncture for culture and PCR is the cornerstone of diagnosis to determine the causative organism and appropriate treatment. Prognosis is excellent in adults and children, with mortality of $<1 \%$ when neonatal mortality is excluded. There are no clear causal links with adverse fetal or neonatal outcomes.

\section{References}

1. Tunkel AR, Scheld WM. Acute meningitis. In: Mandell GL, Bennett JE, Dolin R, editors. Mandell, Douglas, and Bennett's principles and practice of infectious diseases. 6th ed. Philadelphia: Elsevier Churchill Livingstone. 2005; 1083-126.

2. Health Protection Surveillance Centre. Viral Meningitis, not otherwise specified (NOS), in Ireland. Dublin: Health Service Executive. 2018. https://www.hpsc.ie/a-z/vaccinepreventable/viralmeningitis/

3. Desmond RA, Accortt NA, Talley L, Villano SA, Soong SJ, et al Enteroviral meningitis: natural history and outcome of pleconari therapy. Antimicrob Agents Chemother. 2006; 50: 2409-2414. PubMed: https://pubmed.ncbi.nlm.nih.gov/16801419/

4. Chadwick DR. Viral meningitis. British Medical Bulletin. 2005; 75-76: $1-14$.

5. Cassady KA, Whitley RJ. Pathogenesis and pathophysiology of viral infections of the central nervous system. In: Scheld WM, Whitley RJ, Marra CM, editors. Infections of the central nervous system. 3rd ed. Philadelphia: Lippincott Williams \& Wilkins; 2004. 57-74.

6. Nigrovic LE, Kuppermann N, Macias CG, Cannavino CR, MoroSutherland DM, et al. Clinical prediction rule for identifying children with cerebrospinal fluid pleocytosis at very low risk of bacterial meningitis. JAMA. 2007; 297: 52-60.

PubMed: https://pubmed.ncbi.nlm.nih.gov/17200475/

7. Collins S, Arulkumaran S, Hayes K. Oxford Handbook of Obstetrics and Gynaecology. $3^{\text {rd }}$ ed. Oxford: Oxford University Press; 2013.

8. Illia R, Ceretti S, Codoni MJ. Herpetic encephalitis during pregnancy: Case study. MOK Women's Health. 2017; 4: 8-9.

9. Koubaa M, Marrakchi C, Karray H. West Nile virus meningoencephalitis during pregnancy: Case report with MR imaging findings. Egyptian J Radiol Nuclear Med. 2011; 42: 211-214 